\title{
Serum anti-osteopontin autoantibody as a novel diagnostic and prognostic biomarker in patients with hepatocellular carcinoma
}

\author{
XIA YING $^{1 *}$, YUE ZHAO $^{2 *}$, JUN-LAN WANG $^{1}$, XIA ZHOU $^{1}$, JING ZHAO $^{1}$, CHEN-CHEN HE $^{1}$, \\ XI-JING GUO ${ }^{1}$, GUI-HUA JIN ${ }^{1}$, LI-JUAN WANG ${ }^{1}$, QING ZHU ${ }^{1}$ and SU-XIA HAN ${ }^{1}$ \\ ${ }^{1}$ Department of Oncology, The First Affiliated Hospital of Xi'an Jiaotong University Medical College, Xi'an, Shaanxi 710061; \\ ${ }^{2}$ Department of Oncology Radiotherapy, Cangzhou Central Hospital, Cangzhou, Hebei 061001, P.R. China
}

Received May 8, 2014; Accepted June 3, 2014

DOI: $10.3892 /$ or.2014.3367

\begin{abstract}
Osteopontin (OPN) is a secreted phosphorylated and glycosylated protein, which plays an important role in carcinogenesis and metastasis. In hepatocellular carcinoma (HCC), OPN is being investigated either as a therapeutic target gene or as a biomarker for diagnosis. Yet, the role of the anti-OPN autoantibody in $\mathrm{HCC}$ remains unclear. In the present study, the level of serum anti-OPN autoantibody in HCC was analyzed by enzyme-linked immunosorbent assay. Immunohistochemistry (IHC) was also performed to analyze protein expression profiles and the prognostic significance of OPN in HCC. In this study, the prevalence and titer of anti-OPN autoantibodies in $\mathrm{HCC}$ were significantly higher than these values in normal human serum (NHS) ( $\mathrm{P}=0.001, \mathrm{P}=0.000$, respectively). When both $\alpha$-fetoprotein and the autoantibody against OPN were used simultaneously as diagnostic biomarkers, the sensitivity was up to $65 \%$. In IHC, 59 of the $83(65.6 \%)$ HCC specimens expressed OPN with cytoplasmic positive staining. The overall survival (OS) of HCC patients with OPN-positive tumors was 28.81 months compared to 39.37 months for HCC patients with OPN-negative tumors $(\mathrm{P}<0.01)$. Furthermore, multivariate analysis showed that OPN overexpression was the strongest
\end{abstract}

Correspondence to: Professor Su-Xia Han, Department of Oncology, The First Affiliated Hospital of Xi'an Jiaotong University Medical College, Xi'an, Shaanxi 710061, P.R. China

E-mail: shan87@mail.xjtu.edu.cn

*Contributed equally

Abbreviations: HCC, hepatocellular carcinoma; OPN, osteopontin; $\mathrm{CH}$, chronic hepatitis; NHS, normal human serum; AFP, $\alpha$-fetoprotein; SPP1, secreted phosphoprotein 1; ELISA, enzymelinked immunosorbent assay; IHC, immunohistochemistry; IIFA, indirect immunofluorescence assay; OS, overall survival; TAAs, tumor-associated antigens; PVDF, polyvinylidene fluoride; TBS, Tris-buffered saline; RGD, arginine-glycine-aspartate; SIBLING, small integrin-binding ligand N-linked glycoprotein; MAPK, mitogen-activated protein kinase pathway

Key words: osteopontin, autoantibody, hepatocellular carcinoma, biomarker, diagnosis independent adverse prognostic factor for $\mathrm{OS}(\mathrm{P}=0.02)$. Taken together, our data indicate that the anti-OPN autoantibody may be a supplementary serological biomarker for HCC, and is correlated with poor prognosis in HCC patients.

\section{Introduction}

Hepatocellular carcinoma (HCC), the fifth most common cancer worldwide, is not only a highly aggressive carcinoma of the liver but is also the third leading cause of cancer-related mortality (1). Hepatitis B virus, hepatitis $\mathrm{C}$ virus, and chronic heavy alcohol consumption leading to liver cirrhosis remain the most important causes (2). Few target molecules have been identified that enable the diagnosis of HCC with a high sensitivity and specificity, particularly in the early clinical stages of HCC. Currently $\alpha$-fetoprotein (AFP) is widely used as a surveillance and detection test for HCC, despite its limited performance, particularly in early-stage HCC (3). Other molecular markers, for example, lectin-bound AFP (4), glypican-3 (5) and des- $\gamma$ carboxyprothrombin (6) have been proposed for HCC detection. However, an ideal marker for HCC diagnosis and prognosis has not yet been identified. Development of novel biomarkers for the early diagnosis and prognosis of HCC is vital.

Our previous studies demonstrated that cancer serum contains antibodies that react with a unique group of autologous cellular antigens called tumor-associated antigens (TAAs), whose abnormal regulation or excessive expression are closely related to carcinogenesis $(7,8)$. The TAAs in blood circulation rapidly degrade, and their use in early cancer diagnosis has been hampered by false-positive rates in the normal population. In contrast, autoantibodies can identify aberrant cellular antigens in carcinogenesis and serve as markers for cancer detection and surveillance since anti-TAA autoantibodies are more stable (9). Furthermore, the absence of these autoantibodies in normal individuals and non-cancer conditions makes them potential markers for different types of cancer (7). For example, p62, a fetal protein absent in adult tissues, is recognized as a TAA. The anti-p62 autoantibodies were found to be positive in $21 \%$ of HCC patients but negative in controls (10).

Osteopontin (OPN) is a secreted phosphorylated and glycosylated protein, which is expressed widely and has multiple functions in cell adhesion and migration (11), antiapoptosis (12), 
immune and inflammatory responses $(13,14)$, calcification $(15)$ and suppression of nitric oxide synthase (16). In addition, it is also known as secreted phosphoprotein 1 (SPP1). In normal liver tissue, OPN is expressed in bile duct epithelium, stellate cells, and Kupffer cells but not in normal hepatocytes (17). Recent studies have confirmed that OPN plays an important role in carcinogenesis and metastasis $(18,19)$. In many types of cancer, including breast (20), lung (21), colon (22) and kidney cancer (23) elevated expression of OPN was found to be associated with carcinogenesis, progression, metastasis and poor prognosis. Other studies further found elevated expression levels of serum OPN in HCC compared to liver cirrhosis (LC), chronic hepatitis $(\mathrm{CH})$ and normal human serum (NHS) groups $(24,25)$. However, little is known concerning the role of the autoantibody against OPN in HCC and its relationship with the prognosis of HCC patients.

In the present study, the autoantibody response to OPN in HCC and control groups was analyzed by enzyme-linked immunosorbent assay (ELISA) and indirect immunofluorescence assay. Immunohistochemistry (IHC) with an HCC tissue array was also investigated to understand OPN protein expression profiles. In addition, the relationship between OPN expression and overall survival (OS) of HCC patients was analyzed to investigated the role of OPN in the prognosis of HCC patients.

\section{Materials and methods}

Serum samples from $148 \mathrm{HCC}$ patients, 32 patients with $\mathrm{CH}$, 32 patients with LC, and 75 normal controls were collected at The First Affiliated Hospital of Xi'an Jiaotong University (China) from 2011 to 2013. This study was approved by the Ethics Committee of The First Affiliated Hospital of Xi'an Jiaotong University. All HCC serum samples ( $n=148)$ had been collected before patients were treated with chemotherapy, radiotherapy or surgery, and were pathologically confirmed. The normal controls were negative for the hepatitis virus and had no evidence of malignancy. All blood samples were collected in vacuum tubes, clotted at room temperature for $30 \mathrm{~min}$, and then centrifuged at 3,000 rpm for $5 \mathrm{~min}$. The suspension was distributed into $300-\mu 1$ aliquots each and stored at $-80^{\circ} \mathrm{C}$ until analysis. The general information for these patients was available (Table I), and AFP levels of 140 of the $148 \mathrm{HCC}$ serum samples were assessed by ELISA assay.

Indirect enzyme-linked immunosorbent assay (ELISA). Microtiter plates (96-well; Corning, NY, USA) were coated overnight at $4^{\circ} \mathrm{C}$ with $100 \mu \mathrm{l} /$ well recombinant osteopontin protein (R\&D, Minneapolis, MN, USA) at a final concentration of $1.0 \mu \mathrm{g} / \mathrm{ml}$ in phosphate-buffered saline (PBS). Then the plates were blocked with $1 \%$ bovine serum albumin (BSA) in PBS, $300 \mu \mathrm{l} /$ well, for $2 \mathrm{~h}$ at room temperature with gentle shaking. Following 4-time washes with PBST (0.1\% Tween-20 in PBS), $100 \mu \mathrm{l} /$ well diluted human serum (1:50) in 1\% BSA/ PBS was incubated for $2 \mathrm{~h}$ at room temperature in the antigencoated wells with gentle shaking. Plates were washed 4 times again followed by $100 \mu \mathrm{l} /$ well of HRP-conjugated goat antihuman $\operatorname{IgG}$ (1:4000 diluted) for $1 \mathrm{~h}$. After 4 washes, $100 \mu \mathrm{l} /$ well of tetramethylbenzidine (TMB) was added and the reaction was stopped by adding $50 \mu \mathrm{l} 2 \mathrm{M}$ sulphuric acid $\left(\mathrm{H}_{2} \mathrm{SO}_{4}\right)$.
The optical density (OD) of each well was read at a wavelength of $405 \mathrm{~nm}$, and the mean OD of $75 \mathrm{NHS}+3 \mathrm{SD}$ was designated as a cutoff value for a positive reaction.

Cell lines and cell extracts. Ten different cancer cell lines, human hepatocellular carcinoma cell lines (HepG2 and Hep3B), human breast cancer cell lines (MCF-7 and MDA-MB-453), human cervical cancer cell lines (HeLa and $\mathrm{SiHa}$ ), human colorectal cancer cell line (HCT116), non-small cell lung cancer cell line (H1299), prostate cancer cell line (C42), and human epidermal carcinoma cell line (A431), were obtained from the Department of Transformation Medical Center of Xi'an Jiaotong University. Cancer cells were solubilized in extraction buffer supplemented with the protease inhibitor cocktail.

Western blotting. Cancer cell lysates were electrophoresed on $12 \%$ SDS-PAGE and transferred to polyvinylidene fluoride (PVDF) membranes. The membranes were blocked with $5 \%$ non-fat milk in Tris-buffered saline (TBS) at $37^{\circ} \mathrm{C}$ for $3 \mathrm{~h}$ and then incubated overnight at $4^{\circ} \mathrm{C}$ with a 1:1,000 dilution of the rabbit monoclonal anti-SPP1 antibody (Epitomics, Burlingame, CA, USA) and a 1:5,000 dilution of the mouse monoclonal anti- $\beta$-actin antibody (Sigma-Aldrich, St. Louis, MO, USA). HRP-conjugated goat anti-rabbit IgG and HRP-conjugated goat anti-mouse IgG (both at 1:2,000; Abcam Inc, Cambridge, MA, USA) were used as secondary antibodies. An enhanced chemiluminescence kit (Millipore Corporation, Billerica, MA, USA) was used to detect the immunoreactive bands.

Absorption of antibodies with recombinant protein. The serum was incubated with recombinant OPN protein (the final concentration of the protein diluted with HCC serum was $0.01 \mu \mathrm{g} / \mu \mathrm{l}$ ) overnight at $4^{\circ} \mathrm{C}$, and then centrifuged at $10,000 \mathrm{xg}$ for $15 \mathrm{~min}$. The supernatant was the pre-absorbed serum used for the immunofluorescence assay.

Indirect immunofluorescence assay (IIFA). HeLa cells $\left(2 \times 10^{4}\right.$ cells $\left./ \mathrm{ml}\right)$ were cultured in 12 -well plates, after $24 \mathrm{~h}$, serum (1:1) and pre-absorbed serum (1:1) were incubated with these $\mathrm{HeLa}$ antigen substrates overnight at $4^{\circ} \mathrm{C}$. FITCconjugated goat anti-human IgG (Protein Tech Group, Inc., Chicago, IL, USA) was used as the secondary antibody at a 1:20 dilution. Fluorescence microscope (Leica DM1000, Germany) was used for examination.

Immunohistochemical (IHC) analysis of the tissue assay slides. HCC tissue array slides (including 90 HCC tissue specimens) with information regarding clinicopathological characteristics comprising age, gender, clinical stage, pathology grade, and prognosis information were commercially purchased (Outdo Biotech Co., Ltd., Shanghai, China). This tissue assay was used to detect the expression of OPN in HCC specimens and identify the relevant prognostic factors. The protocol for IHC was carried out as previously described (26). The primary antibody was rabbit monoclonal anti-SPP1 antibody (1:120 dilution; Epitomics).

Three independent pathologists evaluated and scored the IHC staining. Scoring of cytoplasmic OPN staining was 
Table I. Characteristics of the patients for ELISA assay.

\begin{tabular}{lccccccc}
\hline & & \multirow{2}{*}{$\begin{array}{c}\text { Age range } \\
\text { Group }\end{array}$} & Mean age & \multicolumn{3}{c}{ Viral infection } \\
\cline { 6 - 8 } & Male/Female & (years) & HBV & HCV & HBV+HCV & No virus \\
\hline NHS & $52 / 23$ & $16-82$ & 51.41 & 0 & 0 & 0 & 75 \\
LC & $28 / 4$ & $27-65$ & 45.91 & 27 & 3 & 0 & 2 \\
CH & $17 / 15$ & $34-73$ & 49.09 & 21 & 10 & 1 & 0 \\
HCC & $123 / 25$ & $14-78$ & 52.95 & 127 & 8 & 1 & 12 \\
\hline
\end{tabular}

HCC, hepatocellular carcinoma; LC, liver cirrhosis; CH, chronic hepatitis; NHS, normal human serum; HBV, hepatitis B virus; HCV, hepatitis $\mathrm{C}$ virus.

Table II. Frequency of the autoantibody against OPN in human serum samples by ELISA.

\begin{tabular}{lcc}
\hline Type of serum & No. tested & Autoantibody to OPN, n (\%) \\
\hline HCC & 148 & $19(12.8)^{\mathrm{b}}$ \\
LC & 32 & $5(15.6)^{\mathrm{a}}$ \\
CH & 32 & $1(3.1)$ \\
NHS & 75 & $0(0.0)$ \\
\hline
\end{tabular}

Cutoff value, mean $+3 \mathrm{SD}$ of NHS samples; ${ }^{\mathrm{b}} \mathrm{P}=0.001$, ${ }^{\mathrm{a}} \mathrm{P}=0.002$ relative to NHS; OPN, osteopontin; HCC, hepatocellular carcinoma; LC, liver cirrhosis; $\mathrm{CH}$, chronic hepatitis; NHS, normal human serum.

based on both the staining intensity and extent according to a previous report (27). Microscopically, each section was observed randomly in 10 high-power fields (x40 magnification), each of which included 100 cells. First, the staining extent was scored according to the proportion of positive tumor cells: 0 , $0 \% ; 1,1-25 \% ; 2,26-50 \% ; 3,51-75 \%$; and 4, 76-100\%. Second, the staining intensity was scored: 0 , no cell staining; 1 , weak staining; 2, moderate staining; 3, strong staining. Finally, scores were calculated by multiplying the intensity and extent scores and the results were divided as follows: negative ('I', score: $0-1$ ), weak positive ('II', score: $2-4$ ), moderate positive ('III', score: 5-8) and strong positive ('IV', score: 9-12). Staining results were also divided into negative expression and positive expression for further study.

Statistical analysis. We adopted SPSS version 18.0 (SPSS Inc., Chicago, IL, USA) for Windows to analyze the data. The mean OD value of each group was compared using the Mann-Whitney U test and the frequency of the autoantibody to OPN in each group of patient serum was compared by means of the $\chi^{2}$ test with Fisher's exact test. Comparison of the clinicopathological parameters with OPN expression was conducted by the two-tailed Mann-Whitney U test. The survival curve was estimated using the Kaplan-Meier method, and the prognostic significance of these markers was analyzed by log-rank test. Univariate and multivariate Cox regression analyses were performed to analyze the relevant prognostic factors. Two-tailed P-values $<0.05$ were considered to indicate statistically significant differences.

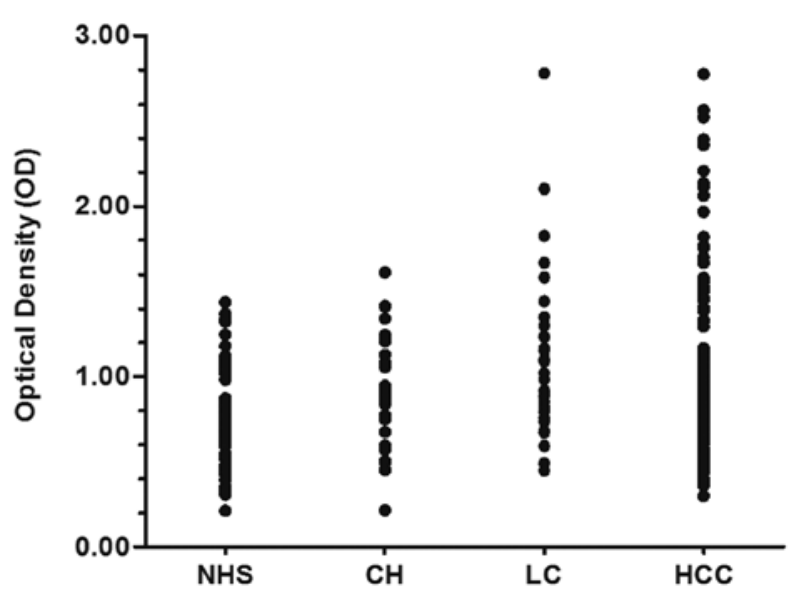

Figure 1. Titer of anti-OPN autoantibodies in human serum samples by ELISA. The range of antibody titers to OPN was expressed as optical density (OD) obtained from ELISA. The mean titer of NHS, CH, LC and HCC was $0.768,0.902,1.087$ and 1.02 , respectively. The mean +3 SD of the NHS samples was used as a cutoff value. Titer of anti-OPN in LC and HCC was much higher than that in the NHS group $(\mathrm{P}<0.001)$. OPN, osteopontin; NHS, normal human serum; $\mathrm{CH}$, chronic hepatitis; LC, liver cirrhosis; HCC, hepatocellular carcinoma.

\section{Results}

Frequency and titer of the autoantibodies against OPN in HCC, LC, CH and NHS groups. Recombinant human OPN protein was used in ELISA as a coated antigen with which to detect autoantibodies against OPN in serum samples from 148 HCC patients, $32 \mathrm{CH}$ patients, $32 \mathrm{LC}$ patients and 75 healthy individuals. The mean titer of the autoantibodies against serum OPN in the NHS group was $0.768 \pm 0.266$, the mean $+3 \mathrm{SD}$ of the NHS samples (1.566) was used as a cutoff value. Table II shows that the prevalence of autoantibodies against OPN was $12.8 \%(19 / 148)$ in HCC, $15.6 \%(5 / 32)$ in LC, $3.1 \%(1 / 32)$ in $\mathrm{CH}$ and $0 \%(0 / 75)$ in the NHS group. Compared with these 4 groups, the prevalence of anti-OPN autoantibodies in the HCC $(\mathrm{P}=0.001)$ and LC $(\mathrm{P}=0.002)$ group was significantly higher than that in the NHS groups. As shown in Fig. 1, the titer of the autoantibodies against OPN in the 4 groups was different $(\mathrm{P}=0.001)$. The titer in the HCC and LC groups was higher than that in the NHS group (both $\mathrm{P}=0.000$ ). The average titer of the anti-OPN autoantibodies was $1.015 \pm 0.502$, $1.087 \pm 0.498,0.902 \pm 0.328$ and $0.768 \pm 0.266$ in the HCC, LC, 


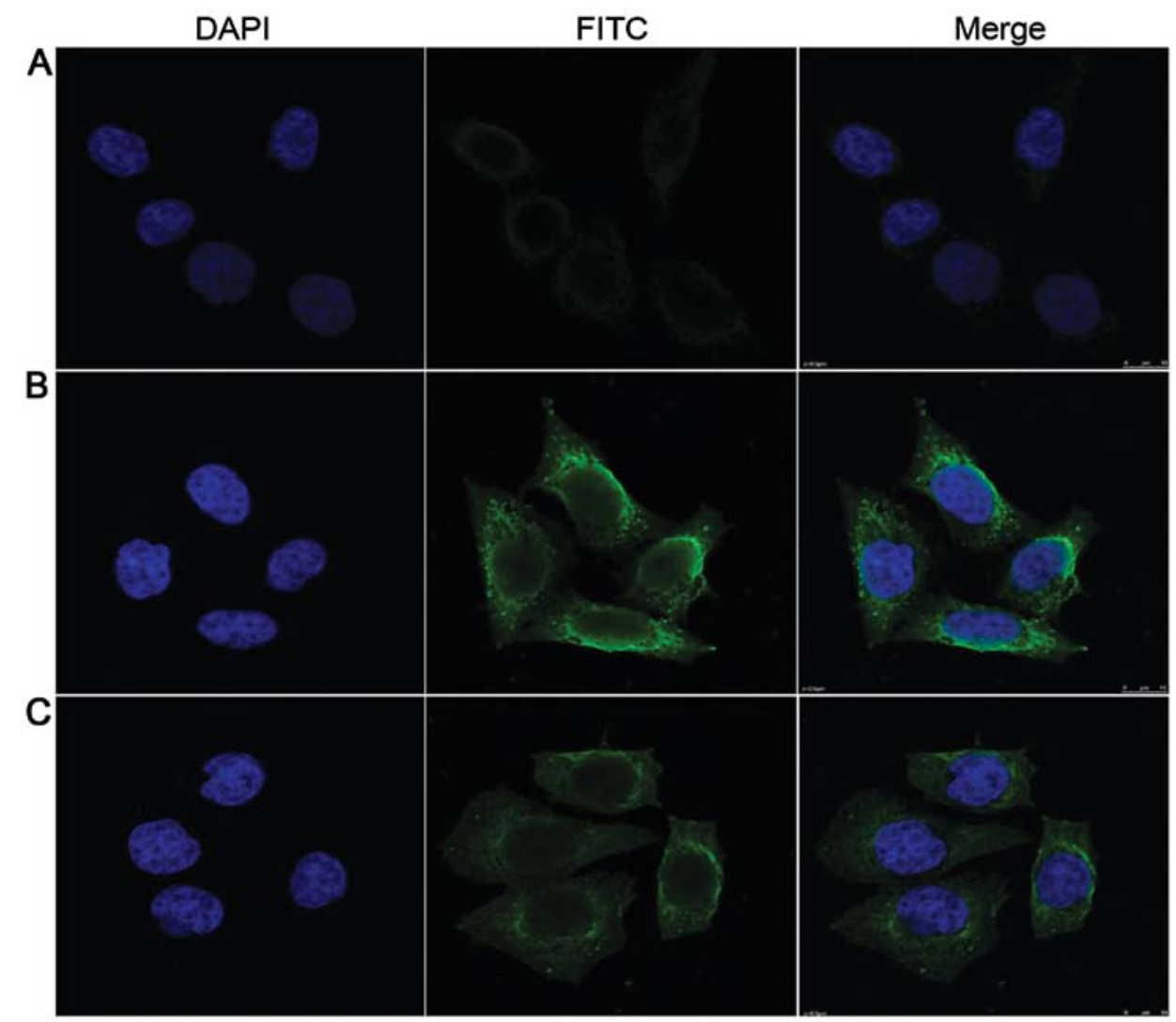

Figure 2. Representative immunofluorescence staining pattern of anti-OPN antibody-positive HCC serum samples. (A) A normal human serum sample. (B) A representative anti-OPN antibody-positive HCC serum sample. (C) The same HCC serum sample in B was pre-absorbed with recombinant OPN protein. OPN, osteopontin; HCC, hepatocellular carcinoma.

$\mathrm{CH}$, and NHS group, respectively. In fact, of the $148 \mathrm{HCC}$ patients, 140 patients were tested for both AFP and anti-OPN autoantibody levels by ELISA. The AFP level in $84(60 \%)$ HCC patients was $>100 \mathrm{ng} / \mathrm{ml}$, whereas in $75(53.6 \%) \mathrm{HCC}$ patients the level was $>200 \mathrm{ng} / \mathrm{ml}$. When both AFP and antiOPN autoantibody were used simultaneously as biomarkers, $91(65 \%) \mathrm{HCC}$ patients (AFP $>100 \mathrm{ng} / \mathrm{ml}$ ) were positive, and 83 (59.3\%) HCC patients (AFP $>200 \mathrm{ng} / \mathrm{ml}$ ) were positive, respectively.

Perinuclear intense staining pattern detected in HeLa cells by indirect immunofluorescence assay with representative positive HCC serum. Indirect immunofluorescence was used to confirm the reactivity of OPN autoantibodies in HCC serum samples and the intracellular location of OPN. In this assay, HeLa cell slides and HCC serum samples with anti-OPN-positive expression in ELISA were selected. As shown in Fig. 2, HCC serum samples with anti-OPN-positive expression had a perinuclear staining pattern. When the same HCC serum samples were pre-absorbed by recombinant OPN protein, the fluorescent staining was significantly reduced.

OPN expression in the different cancer cell lines. OPN contributes to carcinogenesis and metastasis. To determine the expression levels of OPN protein in different tumor cell lines, 10 tumor cell lines (MCF-7, MDA-MB-453, SiHa, HeLa, H1299, HCT116, C42, A431, HepG2, Hep3B) were cultured, and analyzed by western blotting. As shown in Fig. 3, MCF-7,

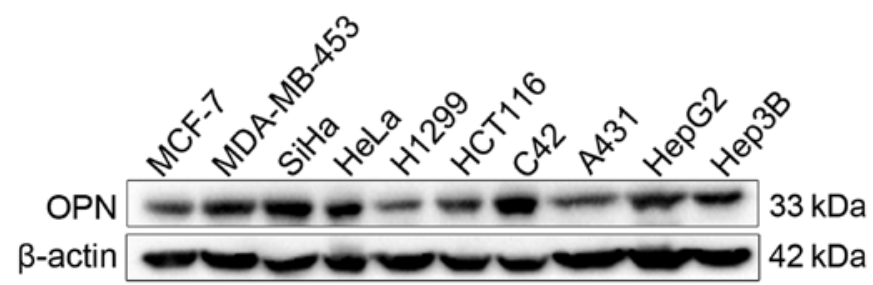

Figure 3. Ten tumor cell lines analyzed by western blotting. The monoclonal anti-OPN antibody was used as a probe. MDA-MB-453, SiHa, HeLa, C42, HepG2 and Hep3B cells exhibited strong reactivity. MCF-7, H1299, HCT116 and A431 cells exhibited weak reactivity compared to the cell lines which had clear reactive bands.

H1299, HCT116 and A431 cancer cell lines showed relatively weaker reactive bands compared to those cell lines that had strong reactivity such as MDA-MB-453, SiHa, HeLa, C42, HepG2 and Hep3B.

Expression of OPN in hepatocellular carcinoma tissues. Expression of OPN protein in the HCC tissues was examined by immunohistochemistry with tissue array slides. The monoclonal anti-OPN antibody was used as a primary antibody to detect the expression of OPN. The expression of OPN showed no correlation with clinical and pathological characteristics such as age, gender, tumor size, histological grade, capsular infiltration and portal vein invasion $(\mathrm{P}<0.05)$. The patients included 77 males and 13 females, with a mean age of $54.51 \pm 9.49$ years (range 18-73 years). The expression of OPN 

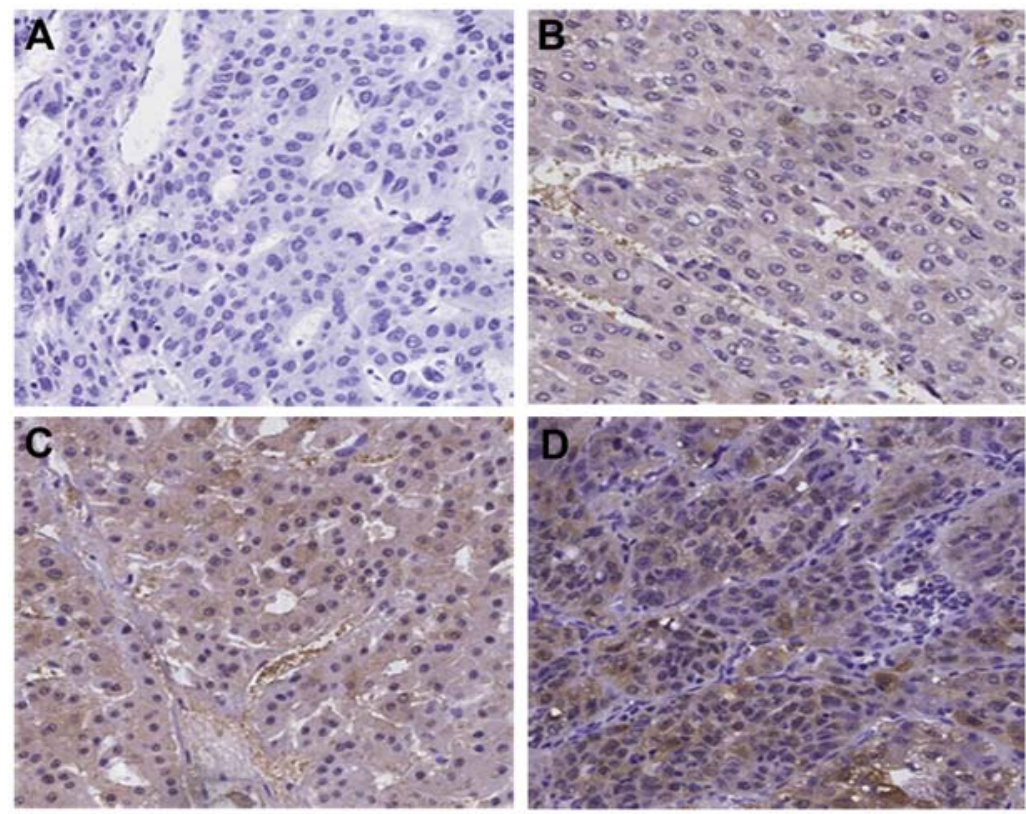

Figure 4. Expression of osteopontin (OPN) in the HCC tissue array. (A) Negative OPN immunohistochemical staining. (B) Weak positive OPN immunohistochemical staining. (C) Moderate positive OPN immunohistochemical staining. (D) Strong positive OPN immunohistochemical staining (A-D: magnification, $\mathrm{x} 200)$.

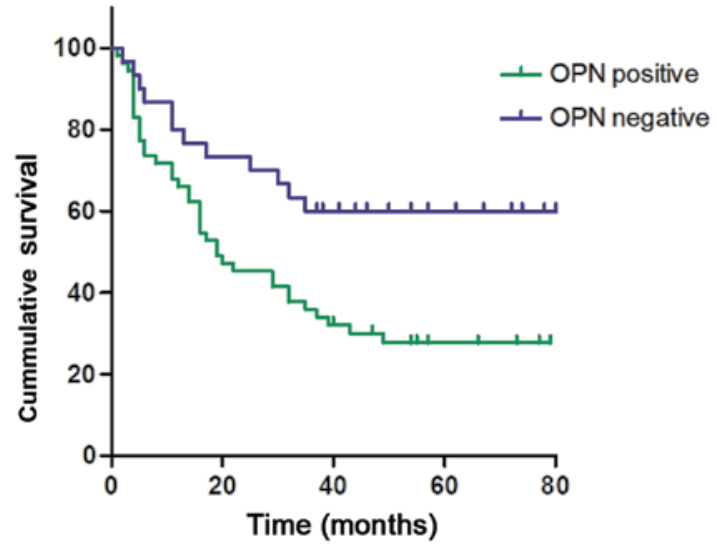

Figure 5. Kaplan-Meier curves for cumulative overall survival of the HCC patients. The HCC patients with OPN-positive expression had a worse survival rate than those with $\mathrm{OPN}$-negative expression. $(\mathrm{P}<0.01)$.

protein in the HCC tissues is shown in Fig. 4. Of the total 90 HCC specimens, $59 \mathrm{HCC}$ samples $(65.6 \%)$ were positive for OPN staining and OPN-positive staining was observed in the cytoplasm of the cancer cells. However, there was no significant correlation between patient age, gender, tumor size, tumor differentiation grade and OPN expression.

Furthermore, the HCC patients of the tissue array slides were followed up over the course of 3-7 years (7 patients were lost to follow-up). At the end of the follow-up period, $33 \mathrm{HCC}$ patients were alive and $50 \mathrm{HCC}$ patients were deceased. We further analyzed the relationship between OPN expression and overall survival (OS) of the HCC patients. Mean OS was $39.37 \pm 23.48$ months in the $\mathrm{HCC}$ patients with negative OPN expression. In contrast, mean OS in the patients with positive OPN expression was $28.81 \pm 24.22$ months. OPN expression was significantly correlated with OS of the HCC patients (Table III). Kaplan-Meier curve and log-rank test
Table III. Univariate analysis of the associations between prognostic variables and overall survival in the HCC patients.

\begin{tabular}{|c|c|c|}
\hline Markers & $\mathrm{n}$ & P-value (OS) \\
\hline Age (years) & & 0.893 \\
\hline$\leq 55$ & 45 & \\
\hline$>55$ & 38 & \\
\hline Gender & & 0.367 \\
\hline Male & 70 & \\
\hline Female & 13 & \\
\hline Tumor size $(\mathrm{cm})$ & & 0.012 \\
\hline$\leq 5$ & 35 & \\
\hline$>5$ & 47 & \\
\hline Histological grade & & 0.432 \\
\hline $\mathrm{I}-\mathrm{II}$ & 52 & \\
\hline III & 31 & \\
\hline Capsular infiltration & & 0.035 \\
\hline With & 2 & \\
\hline Without & 81 & \\
\hline Portal vein invasion & & 0.016 \\
\hline With & 6 & \\
\hline Without & 77 & \\
\hline Lymph node metastasis & & 0.257 \\
\hline With & 1 & \\
\hline Without & 82 & \\
\hline OPN & & 0.009 \\
\hline Positive & 53 & \\
\hline Negative & 30 & \\
\hline
\end{tabular}

HCC, hepatocellular carcinoma; OPN, osteopontin; OS, overall survival. 
Table IV. Multivariate analysis of overall survival according to the Cox model.

\begin{tabular}{lccccccr}
\hline & & & & \multicolumn{2}{c}{$95 \%$ CI for $\operatorname{Exp}(\mathrm{B})$} & & \\
Factors & B & S.E. & Exp(B) & Lower & Upper & Wald & P-value \\
\hline OPN & 0.742 & 0.336 & 2.099 & 1.086 & 4.059 & 4.859 & 0.020 \\
Tumor size & 0.049 & 0.020 & 1.050 & 1.009 & 1.093 & 5.675 & 0.028 \\
\hline
\end{tabular}

B, Cox regression coefficient; $\operatorname{Exp}(\mathrm{B})$, risk ratio; $95 \%$ CI, 95\% confidence interval; OPN, osteopontin.

showed that HCC patients with positive OPN expression had shorter OS than those with negative OPN expression $(\mathrm{P}<0.01)$ (Fig. 5). Overexpression of OPN in HCC is an independent prognostic factor for OS of these HCC patients. Cox multivariate analysis showed that OPN-positive expression and tumor size were prognostic factors (Table IV), and the hazard ratio of OPN expression was 2.099 (95\% CI 1.086-4.059; $\mathrm{P}=0.02$ ). Collectively, these data indicate that $\mathrm{HCC}$ patients with OPN-positive expression have a poor prognosis.

\section{Discussion}

OPN is an arginine-glycine-aspartate (RGD)-containing acidic member of the small integrin-binding ligand $\mathrm{N}$-linked glycoprotein (SIBLING) family of proteins. Various tissues including brain, liver, lung, bone, kidney can produce this protein, and it can be detected in different fluids, for example, blood, urine, milk and seminal fluid (28). Previous studies found that OPN can be produced by activated lymphocytes and macrophages as an early T-cell activation factor and plays a role as a cytokine $(29,30)$. OPN is also a protein with diverse functions due to its different functional domains, such as calcium-binding domain, aspartate-rich domain, heparin-binding domain, thrombin cleavage site, $\alpha 9 \beta 1 / \alpha 4 \beta 1$ domain as well as an integrin-binding RGD motif (31). The multifunction OPN has been revealed in promoting tumor formation and prognosis. It exerts these functions through direct binding to integrin and/or CD44, and the subsequent activation of various pathways leads to an increased malignant phenotype (32). Other studies have also reported the related signaling pathways and mechanisms of OPN. For example, OPN protein can trigger the mitogen-activated protein kinase pathway (MAPK) to promote tumor growth and matastasis, while the effect can be reversed through the knockdown of OPN expression (33). OPN can also induce NF- $\mathrm{kB}$ activity through phosphorylation and degradation of I $\kappa \mathrm{B} \alpha$ by activating IKK that ultimately triggers the activation of pro-MMP-2 (34).

OPN is an attractive potential tumor marker, since it functions not only as an immobilized extracellular matrix molecule but also as a secreted form in body fluids including serum. Previous studies have demonstrated that OPN is overexpressed with invasion and metastasis in a wide variety of human malignancies including HCC $(20,21,24)$. The role of OPN in cancer has recently attracted attention. Our study showed that OPN was expressed at a higher level in MDA-MB-453, SiHa, HeLa, C42, HepG2 and Hep3B cell lines, while expressed relatively weaker in MCF-7, H1299, HCT116 and A431 cell lines. In addition, an immunohistochemistry assay was further used to detect the OPN protein expression profiles. Most importantly, the data showed that the OS of HCC patients with OPN-positive expression was $28.81 \pm 24.22$ months which was significantly shorter than $39.37 \pm 23.48$ months of HCC patients with OPN-negative expression. Furthermore, multivariate analysis showed that OPN overexpression was the strongest independent adverse prognostic factor for OS. Taken together, these results suggest that overexpression of OPN in HCC is related to poor prognosis of HCC patients, which is consistent with the findings of previous studies. Collectively, OPN may be considered as an independent prognostic marker of HCC. Further studies have found that OPN is related to capsular infiltration and portal vein invasion $(25,27)$. Yet, our study did not find a relationship due to the limited pathological information or the small sample size.

However, the role of anti-OPN autoantibody levels in HCC patients is not clearly known although elevated anti-OPN autoantibodies have been detected in prostate cancer (35) and rheumatoid arthritis (36). In the present study, we demonstrated that $12.8 \%$ of HCC patients expressed autoantibodies against OPN, and the frequency and the mean titer of the antiOPN antibodies in HCC serum samples were higher than these values in normal human serum (NHS). However, there was no statistical differences between the HCC group and the LC group or the chronic hepatitis $(\mathrm{CH})$ group, which may be because of the limited patient population of the two groups. Notably, when both the anti-OPN antibody and $\alpha$-fetoprotein (AFP) were used as diagnostic biomarkers simultaneously, the sensitivity of HCC diagnosis reached $65 \%$, which was higher than that using the single anti-OPN autoantibody or AFP as a biomarker. Moreover, indirect immunofluorescence assay was also used to confirm the immune response of the anti-OPN autoantibody in HCC serum samples to recombinant OPN protein. Collectively, these data indicate that the anti-OPN autoantibody may be a potential diagnostic marker for HCC, particularly in conjunction with AFP.

In conclusion, we identified a high level of anti-OPN autoantibody in HCC serum samples and the poor prognosis of HCC patients with OPN-positive expression. It is plausible that OPN and the anti-OPN autoantibody are closely correlated to HCC; both may play an important role in the diagnosis and prognosis of HCC. Further studies with large sample size and detailed pathological information are warranted, and research aimed to investigate the mechanisms of OPN and the anti-OPN autoantibody in carcinogenesis, progression and metastasis will also be proposed. 


\section{Acknowledgements}

We thank Huixun Ren at the Xi'an Jiaotong University School of Medicine for his help.

\section{References}

1. Gomaa AI, Khan SA, Toledano MB, Waked I and TaylorRobinson SD: Hepatocellular carcinoma: Epidemiology, risk factors and pathogenesis. World J Gastroenterol 14: 4300-4308, 2008.

2. Parikh S and Hyman D: Hepatocellular cancer: a guide for the internist. Am J Med 120: 194-202, 2007.

3. Behne T and Copur MS: Biomarkers for hepatocellular carcinoma. Int J Hepatol 2012: 859076, 2012.

4. Cheng J, Wang W, Zhang Y, et al: Prognostic role of pre-treatment serum AFP-L3\% in hepatocellular carcinoma: systematic review and meta-analysis. PloS One 9: e87011, 2014

5. Chen M, Li G, Yan J, et al: Reevaluation of glypican-3 as a serological marker for hepatocellular carcinoma. Clin Chim Acta 423: 105-111, 2013.

6. Song $\mathrm{P}$, Feng X, Zhang K, et al: Perspectives on using des-gamma-carboxyprothrombin (DCP) as a serum biomarker: facilitating early detection of hepatocellular carcinoma in China. Hepatobiliary Surg Nutr 2: 227-231, 2013.

7. Zhu Q, Liu M, Dai L, et al: Using immunoproteomics to identify tumor-associated antigens (TAAs) as biomarkers in cancer immunodiagnosis. Autoimmun Rev 12: 1123-1128, 2013.

8. Zhang Y, Ying X, Han S, et al: Autoantibodies against insulinlike growth factor binding protein-2 as a serological biomarker in the diagnosis of lung cancer. Int J Oncol 42: 93-100, 2013.

9. Tan EM: Autoantibodies as reporters identifying aberrant cellular mechanisms in tumorigenesis. J Clin Invest 108: 1411-1415, 2001

10. Zhang JY, Chan EK, Peng XX and Tan EM: A novel cytoplasmic protein with RNA-binding motifs is an autoantigen in human hepatocellular carcinoma. J Exp Med 189: 1101-1110, 1999.

11. Liaw L, Skinner MP, Raines EW, Ross R, Cheresh DA, Schwartz SM and Giachelli CM: The adhesive and migratory effects of osteopontin are mediated via distinct cell surface integrins. Role of alpha v beta 3 in smooth muscle cell migration to osteopontin in vitro. J Clin Invest 95: 713-724, 1995.

12. Malyankar UM, Scatena M, Suchland KL, Yun TJ, Clark EA and Giachelli CM: Osteoprotegerin is an alpha vbeta 3-induced, NF-kappa B-dependent survival factor for endothelial cells. J Biol Chem 275: 20959-20962, 2000.

13. Chen F, Liu H, Shen Q, et al: Osteopontin: participation in inflammation or mucosal protection in inflammatory bowel diseases? Dig Dis Sci 58: 1569-1580, 2013.

14. Yang M, Ramachandran A, Yan HM, et al: Osteopontin is an initial mediator of inflammation and liver injury during obstructive cholestasis after bile duct ligation in mice. Toxicol Lett 224: 186-195, 2014.

15. Shao JS, Sierra OL, Cohen R, et al: Vascular calcification and aortic fibrosis: a bifunctional role for osteopontin in diabetic arteriosclerosis. Arterioscler Thromb Vasc Biol 31: 1821-1833, 2011.

16. Hwang SM, Lopez CA, Heck DE, Gardner CR, Laskin DL, Laskin JD and Denhardt DT: Osteopontin inhibits induction of nitric oxide synthase gene expression by inflammatory mediators in mouse kidney epithelial cells. J Biol Chem 269: 711-715, 1994

17. Kawashima R, Mochida S, Matsui A, et al: Expression of osteopontin in Kupffer cells and hepatic macrophages and Stellate cells in rat liver after carbon tetrachloride intoxication: a possible factor for macrophage migration into hepatic necrotic areas. Biochem Biophys Res Commun 256: 527-531, 1999.
18. Hahne JC, Meyer SR, Kranke P, et al: Studies on the role of osteopontin-1 in endometrial cancer cell lines. Strahlenther Onkol 189: 1040-1048, 2013.

19. Ramachandran S, Kwon KY, Shin SJ, et al: Regulatory role of osteopontin in malignant transformation of endometrial cancer. Mol Biol Rep 40: 3623-3629, 2013.

20. Li NY, Weber CE, Mi Z, Wai PY, Cuevas BD and Kuo PC: Osteopontin up-regulates critical epithelial-mesenchymal transition transcription factors to induce an aggressive breast cancer phenotype. J Am Coll Surg 217: 17-26, 2013.

21. Yu TT, Han ZG, Shan L, Tao J, Zhang T, Yuan SF and Shen HL: Expression of osteopontin in non-small cell lung cancer and correlative relation with microvascular density. Asian Pac J Cancer Prev 15: 29-32, 2014.

22. Huang J, Pan C, Hu H, Zheng S and Ding L: Osteopontinenhanced hepatic metastasis of colorectal cancer cells. PloS One 7: e47901, 2012.

23. Righi L, Bollito E, Ceppi P, et al: Prognostic role of bone sialoprotein in clear cell renal carcinoma. Anticancer Res 33: 2679-2687, 2013.

24. Shang S, Plymoth A, Ge S, et al: Identification of osteopontin as a novel marker for early hepatocellular carcinoma. Hepatology 55 : 483-490, 2012.

25. Abu El Makarem MA, Abdel-Aleem A, Ali A, Saber R, Shatat M, Rahem DA and Sayed D: Diagnostic significance of plasma osteopontin in hepatitis C virus-related hepatocellular carcinoma. Ann Hepatol 10: 296-305, 2011.

26. Shao Q, Ren P, Li Y, et al: Autoantibodies against glucoseregulated protein 78 as serological diagnostic biomarkers in hepatocellular carcinoma. Int J Oncol 41: 1061-1067, 2012.

27. Xie H, Song J, Du R, et al: Prognostic significance of osteopontin in hepatitis B virus-related hepatocellular carcinoma. Dig liver Dis 39: 167-172, 2007.

28. Ramaiah SK and Rittling S: Pathophysiological role of osteopontin in hepatic inflammation, toxicity, and cancer. Toxicol Sci 103: 4-13, 2008.

29. O'Regan AW, Nau GJ, Chupp GL and Berman JS: Osteopontin (Eta-1) in cell-mediated immunity: teaching an old dog new tricks. Immunol Today 21: 475-478, 2000.

30. Shinohara ML, Jansson M, Hwang ES, Werneck MB Glimcher LH and Cantor H: T-bet-dependent expression of osteopontin contributes to T cell polarization. Proc Natl Acad Sci USA 102: 17101-17106, 2005.

31. Denhardt DT, Noda M, O'Regan AW, Pavlin D and Berman JS: Osteopontin as a means to cope with environmental insults: regulation of inflammation, tissue remodeling, and cell survival. J Clin Invest 107: 1055-1061, 2001.

32. Cao DX, Li ZJ, Jiang XO, et al: Osteopontin as potential biomarker and therapeutic target in gastric and liver cancers. World J Gastroenterol 18: 3923-3930, 2012.

33. Sun BS, Dong QZ, Ye QH, et al: Lentiviral-mediated miRNA against osteopontin suppresses tumor growth and metastasis of human hepatocellular carcinoma. Hepatology 48: 1834-1842, 2008.

34. Philip S and Kundu GC: Osteopontin induces nuclear factor kappa B-mediated promatrix metalloproteinase-2 activation through I kappa B alpha/IKK signaling pathways, and curcumin (diferulolylmethane) down-regulates these pathways. J Biol Chem 278: 14487-14497, 2003.

35. Tilli TM, Silva EA, Matos LC, et al: Osteopontin is a tumor autoantigen in prostate cancer patients. Oncol Lett 2: 109-114, 2011.

36. Sakata M, Tsuruha JI, Masuko-Hongo K, et al: Autoantibodies to osteopontin in patients with osteoarthritis and rheumatoid arthritis. J Rheumatol 28: 1492-1495, 2001. 